\title{
IDENTITY CRISIS AND ASSIMILATION PROBLEMS AMONG SYRIAN REFUGEE WOMEN RESIDING OUTSIDE REFUGEE CAMPS IN JORDAN
}

\author{
Sahar al-Shar and Muhammad al-Tarawneh
}

\begin{abstract}
This article describes and analyzes the main problematic issues of social and cultural assimilation encountered by Syrian refugee women in Jordan who are not living in refugee camps, and the reasons for the identity crisis that these women experience. The data that provide this information were collected by means of semistructured interviews from a sample of 50 of these women. The results show that most of the Syrian refugee women living outside the camps suffered from hardships that interfered with their social and cultural assimilation. There were few formal social relationships between refugee women and others in their milieu, and the refugees felt that there were distinct cultural differences in dialect, customs, and traditions between them and their Jordanian peers. The study shows that most of the participants were living in a state of social isolation resulting from identity crisis. It was difficult for them to develop a sense of belonging to the society of the country of asylum while being distracted both by day-to-day concerns and by their desire to return to their homeland. These factors limited their ability to develop good relations with the host community as a prelude to integration, assimilation, and social symmetry.
\end{abstract}

Keywords: assimilation, identity, identity crisis, Syrian refugees, Syrian female refugees

Sahar al-Shar PhD (corresponding author) is an Assistant Professor in the Sociology Department, University of Jordan, Amman, Jordan. S1987. Email: alshare@ yahoo.com

Muhammad al-Tarawneh is a Professor in the Sociology Department, University of Jordan, Amman, Jordan. Email: Mtarawneh2002@gmail.com 
The forced displacement of people resulting from the growing Syrian crisis and other ongoing crises in Iraq, Afghanistan, and Eritrea is one of today's leading international humanitarian and judicial concerns. When displaced people migrate across international borders, there are repercussions in both the source countries and the countries of asylum. The crisis of the Syrian refugees constitutes one of the most serious humanitarian crises in the world in recent decades. Since the beginning of the crisis, according to a report from the United Nations High Commissioner for Refugees (UNHCR 2014), the number of displaced Syrians has reached about 12 million, of which 5 million have sought refuge in the four neighboring countries of Lebanon, Jordan, Turkey, and Iraq. This amounts to about a sixth of the former population of Syria (United Nations Population Fund, 2016).

A report issued by the West Asia-North Africa (WANA) Institute (Lockhart \& Barker, 2018) pointed out that up to 516,000 refugees had entered Jordan but were not living in the camps allocated for hosting them. This was confirmed by statistics from the UNHCR (2014) stating that $20 \%$ of the refugees were living in five camps: the Za'atari camp, the Mrajeeb al-Fhood camp, the Cyber City camp, the Garden camp in Ramtha city, and the al-Rajhi camp, all of which are located in the northern Jordanian governorates. Because of their proximity to the Syrian border, Jordan's northern governorates bear the greatest burden of hosting Syrian refugees. Za'arour (2014) reported in his study that the Syrian presence there constituted $60 \%$ of all Syrian refugees in Jordan.

A UNHCR (2019) report on the Syrian refugees in Jordan shows that the majority of Syrian refugees are women, children, and the elderly, and that despite the challenges imposed by their harsh circumstances, women were able to be involved in work and in the community and were thus able to bear the burden of meeting their families' requirements, and of adapting to the new circumstances, customs, and culture.

Recently, studies by Al-Salahat (2014) and Aqeel (2013) have addressed the conditions faced by refugee women, especially the economic hardships they encounter. These studies show that being an asylum-seeker often means living with violence and disorder, as well as having difficulty in assimilating into the host community because of fragmentation, isolation, and identity crisis. Several institutions, organizations, and associations, such as the Jordanian Women's Union $^{1}$, the Sisterhood is Global Institute Jordan (SIGI Jordan ${ }^{2}$ ), and the United Nations Children's Fund (UNICEF; 2015), have demonstrated the importance of taking care of women and children who are living in a state of general instability.

\footnotetext{
1 http://jwu.org.jo/Home.aspx?lng=1

2 https://www.annalindhfoundation.org/members/sisterhood-global-institute-jordan-sigi-jmy-mhd-Idwly-Itdmn$\underline{\text { Ins }}$
} 
Understanding assimilation and identity within the asylum community is important when dealing with asylum issues, because the new environment in which refugees find themselves is culturally and socially distinct even when neighbouring countries share similarities in many customs, traditions, ways of living, and religion. As well, local and international institutions concerned with the affairs of refugee women and their families have emphasized that an increasing number of refugee women and their children encounter economic problems due to the absence of a former breadwinner, whether it be a husband, father, or brother. SIGI Jordan (2013) noted that about $36 \%$ of the families registered with them were supported by women who had escaped without their husbands.

Our study draws attention to the hardships and problems that prevent Syrian refugee women from achieving social integration in the country of asylum, and highlights the most important reasons for the identity crisis suffered by many of these women. Thus, this study addresses two main questions:

1. What problems of social and cultural assimilation are experienced by Syrian refugee women who have gained asylum in Jordan but are not residing in a refugee camp?

2. What are the underlying causes of the identity crisis experienced by these women?

\section{Identity Crisis of Refugee Women}

The crisis of asylum for refugee women is not limited to the harsh economic conditions they face and the violence practised against them as refugees. On the contrary, in order to understand the situation of Syrian refugee women residing outside refugee camps, it is necessary to grapple with questions of identity and explore such issues as their relationships with those around them, whether they are able to attempt to improve their lives, and the level of their involvement with the asylum community. Research carried out by UNHCR (2014) and conveyed in a report entitled "Women on their own: Syrian refugee women struggle for survival" showed that a quarter of refugee women run their homes on their own and are in such difficult economic conditions that $78 \%$ of them receive assistance from associations concerned with refugee affairs.

In having been placed suddenly and forcibly into very difficult circumstances, these women are forced to confront central questions of identity, such as "Who am I?" and "To whom do I belong?". These are questions that are often raised as a result of alienation, confusion of values, and marginalization. Alex Mikshelly (1993) defined identity as "an integrated system of psychological, moral, materialistic and social data that involves a pattern of cognitive integration processes and is characterized by its unity embodied in the inner spirit that has a sense and feeling of identity" (p. 129). Burhan Ghalioun (2000) considered that the subject of cultural identity is about neither heritage nor modernity, but about defining one's relationship with others in society while remaining culturally distinct from them. Furthermore, while others, such as Halliday (2000), link personal identity to a national identity with its roots in history, we also know that as an ideology, a personal identity that is grounded in nationalism fosters instability, since national 
International Journal of Child, Youth and Family Studies (2019) 10(4.1): 44-64

identity changes with changing social and political relations; these are the most important components of national identity, along with history, language, and culture (Kinnvall, 2004).

Research on the question of identity is needed in order to understand the relationships among the diverse segments of society, each representing a different cultural or life pattern. This may be a necessary input for planning social systems and education in a manner that facilitates interaction and unity on the basis of diversity. In such planning, the importance of language in the individual's identity and culture must be addressed: language must be considered as identitybearing, given that it plays a fundamental role in the formation of social systems (Avayah, 1986). Each social system produces cultural forms reflected in the customs, social institutions, and relations between members; these social systems make it possible for people to live in groups (Avayah, 1986). Overall, language is an element of identity as well as a means of communication, and is one of the most important elements of determining belonging; it is of no less importance in this regard than religion, which historically has been its rival in terms of importance (Ma'alouf, 1999).

The identity of refugees in the public sphere is different from that in the private sphere (the camps): the identity definition of those residing in the camps is different from that of those outside the camps, as a result of the latter's involvement and interaction with members of the community that has received them. Refugees residing outside the camps have become open to the culture of the other, while the communication of refugees within the camp is based on the refugees' places of origin before asylum. This is confirmed by Al-Zein (2007) in his study showing that Palestinians' identity is based on their culture and their dialect. Al-Zein's study emphasized the role played by culture in shaping the identities of individuals and groups, and saw culture as a meeting of material and spiritual systems that aim to control individuals' behavior so as to improve their identity, their self, and their lifestyle.

As Ermann (2014) showed, because of war, refugees are thrust into a new reality in which they experience the contradictions and differences between their own culture and that of the host. These experiences, which involve harsh conditions and a sudden break with a self-understanding grounded in feelings and webs of significance oriented by one's culture of origin, can lead to a lack of self-understanding and a neglect-based approach to survival coupled with difficulties in adaptation. These lead in turn to a sense of alienation from others, and to those others considering the refugee or incoming person as estranged.

In this vein, Abdul-Ghani (2016) noted that the most important aspects of identity are those transmitted within the group, and that these aspects maintain their vitality based on their ongoing contribution to the maintenance of identity. In practice, it is difficult to deconstruct the strong association between the identity of the individual and the identity of the group (Abdul-Ghani, 2016). Abdul-Ghani also stated that a key contributor to identity is social upbringing, a natural mechanism that strengthens the association between the individual and the group at several levels. Social upbringing does its work by associating the individual identity with the group (collective) 
identity and promoting the sense of belonging to the group within the individual — that is, pushing the individual to adapt to the society's prevalent social, moral, political, economic, and religious values (Abdul-Ghani, 2016). The social upbringing mechanism is important in preserving identity and enhancing the individual's sense of the surrounding community, especially for those who suffer from shocks that could undermine their trust in others; the social upbringing mechanism can maintain this trust, but if that mechanism is disrupted, difficulties can arise (Abdul-Ghani, 2016).

Abdul-Ghani (2016) pointed out that adaptation within the control mechanisms contributes to adjusting to new circumstances despite difficult conditions or personal tragedies, and to avoiding becoming secluded within the boundaries of narrow self-identity (isolation). Social upbringing, therefore, contributes to strengthening the association of individual identity and collective identity, as the individual identity helps to ease the acceptance of others without eliminating belonging to others. We see that one's identity is deeply rooted in social structures: the identity of the individual represents an outside threat at the emergence of cultural specificities, while the collective identity strongly reshapes the identity of the individual in line with the general cultural field (Abdul-Ghani, 2016).

Following Haidar (1997), we raise the possibility that Syrian refugee women are positioned between two poles when raising the issue of identity, especially if they are not sufficiently aware of belonging to their Syrian culture of origin and its possible connections to the culture of Jordan, the country in which they now live. Thus, Syrian refugee women may be caught between isolation and fragmentation on the one hand, and between integration, interaction, and openness on the other. Their attempts to interact within mutual social relations, especially outside the camps, could contribute to a form of natural integration based on cultural openness to new societies. As Haidar noted, the personal identity of individuals within any society is that which is in confrontation and conflict with its present circumstances, which means that it is not a once-and-for-all experience. One's living identity is engaged in a continuous production of its own (Haidar, 1997).

\section{Additional Frameworks that Contribute to Understanding Identity Challenges in Refugees}

\section{Trauma Theory}

As long ago as the post-World War II years, Murphy (1955) asserted that refugees must ultimately come to terms with what they have lost: their homeland, identity, and past life, in addition to suffering trauma, oppression, and loss of those whom they love. Refugees then have to face a new life in a strange land of which they know little, while also dealing with anxiety, fear, frustration, and emotional disturbance. In these circumstances, the refugees may become apathetic or aggressive, and so lose the capacity to coordinate, predict, and anticipate events (Murphy, 1955). More than forty years later, Hyndman (1999) confirmed that women refugees suffer from trauma before and during asylum and after settling down, while always also having to deal with being at risk for other painful gender-based experiences such as sexual assault and rape. All these experiences play a role in determining the success of the refugees who seek asylum, which in itself is a form of trauma. Rashedi (1999) showed that the convergence of these multiple pressures 
creates circumstances in which people exhibit various degrees of adaptation and noted that the trauma of the refugees is accompanied by fear, anxiety, stress and psychological symptoms such as depression, helplessness, and denial.

With regard to refugees, several sets, or clusters, of factors have been identified as either aiding adjustment, or tending to increase mental health challenges: loneliness or isolation; changes in life situation, especially with regard to work; generational conflict among refugees themselves; and cultural shock (Zwingmann, 1978). Cluster boundaries are not precisely defined; they often interact closely with one another and with the factors that contribute or limit refugee adaptation and assimilation in the country of asylum, specifically among refugee women.

Baskauskas (1981) discussed the adjustment of refugees in terms of a grief process and indicated that this adjustment has three stages: (a) conservatism, a defensive mechanism to maintain continuity and preserve and hold on to the past; (b) bereavement (emotional mourning), an admission of irretrievable loss; and, (c) innovation, a movement beyond one's loss in order to develop a new way of life. However, as Baskauskas pointed out, the bereavement stage is the most important of these for refugees, especially if it lasts a long time, either because their homeland is permanently lost to them, or because the refugees identify so strongly with their nation that they cling to the hope of returning, delaying their psychological adaptation to the new society.

Refugees often find themselves in ambiguous situations where they have difficulty predicting the behavior of others. As refugees attempt to redefine their life situations and adopt strategies to deal with the crises they face, they begin to discover that their past life experiences have not adequately prepared them to live in a different culture (Taylor \& Nathan, 1980).

Based on what we have described above, we suggest that the trauma of asylum for Syrian women may begin with the lack knowledge of acceptable and unacceptable behavior patterns in the new environment (Jordan). This is especially true for those who live independently away from the camps. They may suffer from insomnia and stress, and are always under pressure to become more compatible with the new environment.

\section{Assimilation Theory}

Milton Gordon's (1964) foundational analysis of refugee assimilation comprised three key elements: the assimilation model itself, the role of the refugee community or the ethnic group, and the nature and form of the assimilation process. Gordon defined the assimilation process as one of leaving behind one's original cultural identity as a singular source of self-description and moving towards a location of self in the larger society. According to Gordon, this process necessarily involves the newcomer learning the culture and behavior of the dominant society.

Gordon (1964) also noted that there are three models of assimilation in relation to refugees: (a) conformity, or more closely matching the host; that is, the refugee moves towards full acceptance of the prevailing culture; (b) integration or "melting pot", an idea of American origin 
that regards both indigenous peoples and refugees to have changed and merged into a better alloy; and, (c) multiculturalism, in which the refugee will adopt the dominant culture, especially in politics, recreation, education, and labor, but will preserve his or her personal way of life and many facets of his or her culture.

Before Gordon (1964), Eisenstadt (1954) had argued that for refugees to reach the highest level of adaptation and assimilation, they must pass through the process of absorption within the process of assimilation. This process takes place in four stages: (a) acquisition of language (including the dialect of the region), norms, and roles; (b) learning to perform a set of new roles for dealing with the many new situations that will occur; (c) developing a new identity, self-image, values, and patterns of self (basic personal adjustment); and, (d) movement from participation in the institutions of the ethnic group of origin to participation in the institutions of the host society.

Gordon (1964) considered these phases, especially the first three, to constitute behavioral assimilation or symmetry - learning the cultural patterns of the new country — and argued that this corresponds to the long-term existence of ethnic subgroups. Gordon called the fourth stage structural assimilation, which is entering into the life of the primary group of the new land. This occurs when members of the ethnic subgroup marry into the primary group; join clubs; acquire new identities that fit the host society; are no longer subjected to prejudice, bias, and discrimination; and no longer have value conflicts with members of the host community. This structural absorption is a precondition for ideal and total assimilation - a complete merging of refugees into the local society.

Based on what we learned from our own study, and considering the absorption process with its four phases, for a Syrian refugee woman to engage seriously in the labor market and in the social life of the host country she must learn the languages or dialects used by neighbors and friends; only then will she acquire the ability to learn new roles in the new culture. Holding on to the old without being able to participate in the new will leave her in a state of contradiction and in a crisis of assimilation. Therefore, developing an identity commensurate with the general identity of the host country (Jordan) enables Syrian refugee women, over time, to participate in different interactive social institutions.

This assimilation does not occur overnight. On the contrary, it passes through the phases addressed by Eisenstadt (1954), in which assimilation begins with acquiring skills in the first few months. Eisenstadt characterized this phase as stressful for almost all refugees regardless of gender; if they acquire some mastery of colloquial communication in the first and second year, they become capable of learning new roles within the second phase. This gives them some control over the changes to their lives that occurred during the journey to asylum, changes that were necessary in order to survive. After four years of asylum, the adjustment becomes clear in their behavior and identity, as the first phases have gradually passed, and the refugee has undergone real change. 
International Journal of Child, Youth and Family Studies (2019) 10(4.1): 44-64

The theory of assimilation developed by Alejandro Portes (Portes and Rumbaut, 2001), who began his research on this topic in the United Sates in the early 1990s, focuses on the migrants' circumstances as experienced between two generations of immigrants and the wider ethnic community, and describes the possible results in the second generation (children of migrants). In their article examining theories of assimilation using data from New York, Waters, Tran, Kasinitz, and Mollenkopf (2010) stated:

Segmented assimilation theory posits three possible outcomes for the second generation: upward assimilation, downward assimilation, and upward mobility combined with persistent biculturalism. These paths correspond to three processes that summarize the relations between immigrant children, their parents, and the wider ethnic community - consonant, dissonant, and selective acculturation. (para. 6).

We may employ these three possible outcomes described by Portes and Rumbaut (2001) with regard to Syrian refugee women in Jordan living outside the camps in order to understand the levels of assimilation that the refugees have reached since the beginning of the Syrian crisis. According to Waters and colleagues (2010), in the United States,

consonant acculturation occurs when the children and parents both learn American culture and gradually abandon their home language and "old country" ways at about the same pace. As these children enter the American mainstream, they achieve upward mobility with the support of their parents. Dissonant acculturation occurs when children learn English and adopt American ways far faster than do their immigrant parents. Portes and Rumbaut (2010) argue that this process can lead to downward assimilation when these young people confront racial discrimination [and] bifurcated labor markets on their own without strong parental authority or community support. The third process, selective acculturation, leads to upward assimilation and biculturalism. This occurs when parents and children both gradually learn American ways while remaining embedded, at least in part, in the ethnic community. (para. 6)

Alba and Nee (2003) applied the theory of assimilation to immigrants in the United States of America when considering the impact of new communities on the first and second generation children, the extent of their integration into society, and the impact of the new community on the culture of the immigrants. Their work helps to expand assimilation theory by providing a better understanding of the integration of immigrants. Alba and Nee (2003), while retaining key insights from earlier theorists, predicted that most members of the current second generation (i.e., the children of immigrants) will experience increasing social integration and upward mobility. However, they rejected the prescriptive assertion that second generation immigrants need to adopt "American norms" (or those of any other dominant culture) and stressed the fact that the American society "mainstream" is highly dynamic and heterogeneous. 
These theoretical pathways that describe assimilation theory may be helpful to our understanding of Syrian refugee women in the asylum community, and may offer some perspectives with regard to our understanding of the children of Syrian refugee women who may be slowly absorbing the culture of Jordanian society. Overall, we suggest that the experiences of refugee women and children may produce constant acculturation between the refugee community and the host community, and with it, upward assimilation. Some members of the first-and-second generation refugee community may take on the culture of the new society more rapidly than others, which can lead to a gap between the first generation and the second with respect to the culture of the new society, and therefore to a dissonant acculturation where parent-child bonds are concerned. This in turn can lead refugees and their children to having distorted views of each other's engagement and integration within the culture of the host society.

Learning the culture of the new society while retaining an identity based in connection to the old culture in difficult conditions leads to the third case developed by Portes and Rumbaut (2001). This takes the form of the upward assimilation of refugees and their second-generation children with the possibility of maintaining a dual culture. This situation is very close to the social integration that the refugee may achieve over time as described by Alba and Nee (2003).

Beyond the research described above focusing on the accumulated assimilation process, there are few studies dealing with the alienation and identity crisis of refugees. Among these we found the work of Mikshelly (1993), who carried out a study of the changes associated with the maturing of the individual refugee identity. Mikshelly asked his research participants to answer the question, "Who am I?" 20 times in a row in a different way each time. He found that the responses first referred to social categories (age, sex, and occupation), then to social roles (fathers, brothers, etc.) and then to political affiliations. The results showed that the concept of identity is varied in its meanings and terminology and that identity is referenced at the individual, group, and cultural levels. Furthermore, this suggests that an individual's identity is a changing and evolving concept, one that in the course of its development comes to define the distinctiveness of each human being.

We also located the work of Mubayyed (2010), which has relevance to the psychological trauma and isolation of refugees, and to their difficulty in assimilating into the host society. Mubayyed examined the various issues and conditions faced by Palestinian refugees in general, and of those in the Balata camp in the West Bank in particular. The key finding of this research was that the refugees in the Balata camp felt politically alienated, as indicated by their feelings of isolation, rebelliousness, and non-adaptation.

Finally, we found one study that focused on Syrian refugee women in Jordan who are not living in a refugee camp. The study was conducted by Al-Salahat (2014), who sought to identify the psychological and social problems that Syrian refugee women encounter in the Za'atari camp. This study concluded that refugee women suffer from psychological problems, of which the most severe is post-traumatic stress disorder, followed by depression and anxiety and other 
psychophysical problems. Al-Salahat also found that these women suffered from social problems, mainly to do with the environment in which they found themselves and the ensuing difficult social relations, and from grief over the loss of their relatives and other loved ones.

Given the paucity of information about refugee women in general, and about Syrian refugee women in Jordan who are not living in a refugee camps in particular, we conducted the study that we report on here. We addressed two main questions: "What problems of social and cultural assimilation are experienced by Syrian refugee women residing in Jordan, but not in a refugee camp, after gaining asylum there?" and "What are the underlying causes of the identity crisis experienced by these women?"

\section{Method}

\section{Population and Participants}

The study population consisted of all Syrian refugee women in the city of Irbid in northern Jordan and its villages, who were living outside the refugee camps that are designated for receiving Syrian refugees in Jordan. The UNHCR (2014) report on the struggles for survival of Syrian women on their own pointed out that only about $20 \%$ of Syrian refugees live in camps, while the rest live outside the camps and are involved in their local communities. Since 2015, the Jordanian Women's Union has provided social and psychological services, in-kind assistance, and various courses for refugee women and has involved them in projects aimed at economic and social empowerment, while also raising awareness of the importance of these women's rights through the Union's family guidance line. From the beginning of the Syrian crisis until the end of 2017, 1,326 Syrian refugee women in Irbid residing outside the camps visited the Jordanian Women's Union there. Our study sample consisted of 50 of these women. A recorded, semi-open interview was the main data collection instrument employed. The questions are listed in Tables 2 and 3 below. Although the interview sessions were focused on asking questions and recording the answers, they also allowed us to observe the participants' responses and to gauge the extent of their cooperation and to ask supplementary questions. The participants were interviewed in their homes after setting appointments in coordination with researchers in the Jordanian Women's Union. Demographic data about our participants are provided in Table 1 below. 
International Journal of Child, Youth and Family Studies (2019) 10(4.1): 44-64

\section{Results}

Table 1. Characteristics as a Percentage of the Sample

\begin{tabular}{|c|c|c|}
\hline Characteristic & $f$ & $\%$ \\
\hline \multicolumn{3}{|l|}{ Age } \\
\hline $20-40$ & 29 & 58 \\
\hline$>40$ & 21 & 42 \\
\hline \multicolumn{3}{|l|}{ Marital status } \\
\hline Married & 39 & 78 \\
\hline Divorced & 6 & 12 \\
\hline Widow & 3 & 6 \\
\hline Single & 2 & 4 \\
\hline \multicolumn{3}{|l|}{ Educational level } \\
\hline Illiterate & 18 & 36 \\
\hline Secondary & 26 & 52 \\
\hline $\mathrm{BA}$ & 3 & 6 \\
\hline Diploma & 3 & 6 \\
\hline Postgraduate degree & 0 & 0 \\
\hline \multicolumn{3}{|l|}{ Asylum duration } \\
\hline 1 year & 1 & 2 \\
\hline 2 years & 4 & 8 \\
\hline 3 years or more & 45 & 90 \\
\hline \multicolumn{3}{|l|}{ House } \\
\hline Owned & 0 & 0 \\
\hline Rented & 50 & 100 \\
\hline \multicolumn{3}{|l|}{ Husband presence } \\
\hline Available & 39 & 78 \\
\hline Not available & 11 & 22 \\
\hline \multicolumn{3}{|c|}{ Husband employed after asylum } \\
\hline Has a job & 32 & 82 \\
\hline Doesn't have a job & 7 & 14 \\
\hline \multicolumn{3}{|l|}{ Number of children } \\
\hline $1-4$ & 7 & 14 \\
\hline 4 or more & 43 & 86 \\
\hline \multicolumn{3}{|c|}{ Woman employed before asylum } \\
\hline Had a job & 8 & 16 \\
\hline Never had a job & 42 & 84 \\
\hline \multicolumn{3}{|c|}{ Woman employed after asylum } \\
\hline Has a job & 49 & 98 \\
\hline Doesn't have a job & 1 & 2 \\
\hline
\end{tabular}

Note: $\mathrm{N}=50$. 
Table 1 shows that most of the refugee women in the sample were between 20 and 40 years old. This is correlated with their ability to encounter challenges and assume the responsibilities and burdens of the circumstances that accompanied their asylum. Of the women who were living with their husbands, the husbands had a job after asylum in $82 \%$ of cases; however, these women pointed out during interviews that the husband's work alone was not enough to meet the family's needs. Husbands often had to change jobs as a result of the continual pursuit by the authorities of those Syrians who were able to find work because Syrian refugees are not given official permits to work in Jordan. The interviews showed that the women were forced to work to cover the shortfall in family expenses and that both husbands and wives constantly had to deal with the possibility of losing their jobs.

Most $(86 \%)$ of the refugee women had not worked before asylum. After being given asylum in Jordan, $98 \%$ of participants worked. The implications of this are reflected in the level of education. Our results indicate that the majority (52\%) of the interviewed women had achieved a modest level of education up to less than the secondary level. This played a role in their inability to work before asylum. One participant said, "I was not used to having to work; I have never thought in my life that I would become a servant." Another refugee woman agreed, saying, "Had I known that the end of my coming to Jordan would be raising the children of my neighbors, I would have preferred to stay in Syria, which is far more merciful."

Having a husband whose economic contributions have been reduced by unemployment, underemployment, or low wages was a clear and tangible change of circumstances for the married refugee women. This involved a change in their perception of work, and in their ability to get paid by their own efforts and so help support the family. This was shown when one participant said, "I have to go out to work. Life is hard here and I have to cooperate with my husband." Another said, "No matter how much aid we obtain, it is insufficient, and so I have to work so that my children will be secure." These statements indicate the urgent necessity for women to work and contribute to household expenses.

During the asylum journey, most women (80\%) and their children were accompanied by their husbands. The participants confirmed that they were unable to escape the crisis without either a husband or an alternative breadwinner such as a father, older brother, or uncle on whom they had been mainly dependent before asylum. In this regard, one participant commented:

Had it not been for my elder brother, may Allah protect him, we would not have been able to travel, or to move from one place to another. We are all females. My mother accompanied us, and this is the greatest reason for our departure. It makes us feel safe to be a group of females.

We see this as a clear expression of the need for a basic breadwinner in the life of a refugee woman, especially during the journey to seek asylum. Both the refugees' own culture and the host society consider males in the family (husband, father or brother) to be a source of social, economic, and 
psychological stability for refugees. Their absence therefore makes an already precarious situation even worse. The results of this study are inconsistent with the figures that reported by SIGI Jordan since this study conducted outside the refugee camps where women were overwhelmingly with their husbands.

\section{Issues of Social and Cultural Assimilation}

Table 2 shows that, after asylum, participants were in a state of emotional and intellectual agitation due to their lack of a sense of compatibility with the new society. This was despite having established somewhat successful social relations within their new social milieu. However, these relations tended to occur in work contexts only, not in the personal social sphere: the percentage of social relations within the work environment was $66 \%$, whereas the percentage of social relations within the neighborhood, combined with personal relations, was only $26 \%$.

Table 2. Issues of Social and Cultural Assimilation

\begin{tabular}{lrr}
\hline Issue & $F$ & $\%$ \\
\hline Compatibility in community & & \\
$\quad$ Yes & 21 & 42 \\
$\quad$ No & 29 & 58 \\
Others' acceptance of refugee women & & \\
$\quad$ Yes & 17 & 34 \\
$\quad$ No & 33 & 66 \\
Good social relationships & & \\
$\quad$ At work & 33 & 66 \\
$\quad$ With neighbors & 13 & 26 \\
$\quad$ No relations & 4 & 8 \\
Similarity of customs and traditions & & \\
$\quad$ Little difference & 11 & 22 \\
$\quad$ Great difference & 39 & 78 \\
\hline
\end{tabular}

Note: $\mathrm{N}=50$.

Approximately $42 \%$ of the participants felt they were compatible with the surrounding society, while $58 \%$ felt incompatible. Several circumstances experienced by the latter contributed to this difference, most importantly: (a) lack of adequate medical aid; (b) inadequate housing due to economic hardship; (c) exposure to multiple forms of verbal and other humiliation; and, (d) persistent nostalgia for the homeland, leading to an inability to adapt to the new circumstances.

When asked about her psychological state of being in a country other than her native homeland, one participant said, "I am confused and stressed. I feel suffocated as there is nothing here (in Jordan) that gives me ease of mind." Another woman said, "I wonder why the world is so cruel to us in this way - there is nothing to please us." The women's statements show that they were suffering from a state of hidden agitation that they were trying in vain to overcome. Another refugee expressed her state of psychological disorder and her confusion of sad feelings by saying: 
International Journal of Child, Youth and Family Studies (2019) 10(4.1): 44-64

I have been here in Jordan for seven years, and even today I weep every day, feeling sad as the picture of my home does not leave my imagination; nor does the image of my family who stayed there in the Levant while we came out here.

This shows an element of longstanding nostalgia for the times, places, and people this participant had known. Another refugee woman replied, "Sister, never believe that refugees feel happy about alienation from their country.... All of them are distressed but they are trying to hide it and I am the first to hide it." In spite of being caught in a confusion of negative feelings and ideas, refugee women have a clear ability to hide their tension and grief from their children and family members.

The lives of such participants had been shaped by this state of agitation and other negative feelings. They had experienced a depth of grief that they had not been familiar with before asylum. Despite their many attempts to overcome these sad feelings, which were a barrier to their integration, the feelings had lasted for a relatively long time. Now, when contemplating the fabric of their new social relations, some of the refugee women only saw in themselves misery, agitation, and internal imbalance. Therefore, the results of this study show a degree of compatibility with the surrounding society of non-refugees that varied only slightly.

As for whether the refugees felt they were accepted by others in society, the results of the study show that $66 \%$ of participants felt they were not accepted by the people of Jordan, while only $34 \%$ felt accepted. Acceptance by the host population is one of the necessary elements for assimilation. It is impossible to adequately address matters such as compatibility, assimilation, and harmony in a society that rejects a particular category of people.

One refugee woman said, "Many people refuse to employ us just because we are Syrians." Another gave an example of the refusal of some neighbors to have social contact with them, saying, "I tried to visit the neighbors more than once, but some of them apologized and many of them did not pay me a visit back. They said, 'We do not want relationships, do you understand?' "'

\section{Main Problems Underlying the Identity Crisis of Syrian Refugee Women}

The results of the present study show that our participants were experiencing what can be termed an identity crisis. One main problem underlying this crisis was that the majority (72\%) of the women in the sample felt unable to accept the people of the host community. Clear differences between the culture of Syria and the culture of Jordan - different customs and traditions underlay this rejection, although $42 \%$ of participants felt that the symbols and semantics of these two cultures show a nearness and general similarity. The difference lay in details of content, which led the majority of participants to reject the new culture: they preferred isolation to learning a new way of life.

There was also a clear correlation between the extent to which the participants were accepted by those in the asylum society and their willingness to identify themselves as Syrian 
refugee women. Approximately $66 \%$ of the women interviewed either hid their identity or, at least, did not introduce themselves as refugees or as Syrians at their first meeting with a new acquaintance, whether it was in the vicinity of the home, at work, or elsewhere. For some, their identity was revealed through their dialect or through the use of customs or traditions unfamiliar to Jordanians. One of the refugee women said, "I don't like to say that I am Syrian because I feel that people start to sympathize with me." According to another participant, "When I say that I am Syrian, people look upon me as if I were defective." Another refugee woman explained not being accepted by saying, "Jordanians don't accept us. They think we are beggars, or that we came to rob their houses and their lands." Findings about our participants' identity crises are given in Table 3.

Table 3. Identity Crisis

\begin{tabular}{lll}
\hline Issue & $f$ & $\%$ \\
\hline Acceptance of those around them & 14 & 28 \\
$\quad$ Yes & 36 & 72 \\
No & & \\
Difficulty understanding the spoken language & 32 & 64 \\
Yes & 18 & 36 \\
No & & \\
Symbols and semantics between the two cultures are & & 42 \\
similar & 21 & 58 \\
Yes & 29 & \\
No & & 84 \\
Persistent desire to return to the homeland & 42 & 16 \\
Yes & 8 & 34 \\
No & & 66 \\
Revelation of Syrian identity to the host community & 17 & \\
Declared & 33 & \\
Concealed & & \\
\hline
\end{tabular}

Note: $\mathrm{N}=50$.

Despite the identity-related concerns expressed by the majority of our participants, $34 \%$ of those we interviewed declared their identity as refugees and did not hesitate to do so, and considered seeking refuge to be a necessity that any woman or any society might encounter, given that no country is immune to crises, calamities, and natural disasters. One participant said, "I am not ashamed to say that I am Syrian. Being a Syrian is not shameful. What has occurred to us might occur in any country, so why should I be ashamed?" Another explained her willingness to reveal her identity by saying, "I feel that I am among my family; they don't treat me as if I were a stranger." 
Revelation of Syrian identity was clearly correlated with the extent to which participants felt accepted by others. The results of the study show that $66 \%$ of participants felt they were not accepted by the surrounding society, while $34 \%$ felt welcomed (see Table 3); these are the same percentages as those for participants' preference for concealing or declaring their identity. These results imply that the refugees in our study population considered that their social relations succeeded only when they did not hesitate to declare or disclose their identity. Identity disclosure is an important part of the establishment of labor relations, social relations with neighbors, and even kinship and marriage.

Most of the participants (90\%) had been in Jordan for three or more years. Residing outside the refugee camps provided them with a chance to establish good relations beyond the boundaries of their old traditions. To explore the extent of assimilation that had been achieved, participants were asked whether they had made changes to the terminology that they used in the context of social transactions. Their responses showed a pronounced impact of the past in many contexts; for example, citing a particular proverb or comparing prices or in relation to certain traditions and customs. One refugee said, "Here, you feel that everything is different. Even their wedding parties and what goes on at consolation houses and family management are completely different." Another participant, addressing a favorable estimate of the extent of assimilation with the current society, pointed out:

Your prices of vegetables and fruit are more expensive than ours, in addition to the prices of clothing that make you feel that it is not the same in Jordan which is located near to Sham (Syria), still everything is cheaper there.

The study has also revealed a state of alienation due to the differences between the two countries and their cultures. However, this finding is contradicted by al-Zein (2007) in a study that addressed Palestinian identity in their culture and their dialect: Palestinian refugees who live outside camps developed an openness to the others' host culture as a result of their involvement and interaction with the host community, whereas the communications of refugees within camps were largely restricted to compatriots. In this regard, one of the Syrian refugees we interviewed pointed out, "Sometimes, I feel lost, not knowing what to say or where to go."

Our study also revealed that, as Baskauskas (1981) and Loizos (1975) noted (see "Trauma Theory" above), refugee adaptation is carried out through the three-stage grief process of conservatism, bereavement, and innovation. But in the case of our study, Table 3 shows that bereavement, indicated by a sustained desire to return to the homeland, was experienced by the majority (84\%) of the women interviewed, even though most had been living in Jordan for 5 to 7 years. We therefore suggest that the prolonged period of bereavement had limited the degree of harmony and adaptation to the new culture that the women were able to achieve, influencing the depth of social relations and causing an inability to overcome the difficult new circumstances. 
In another context, the results of our study are consistent with Eisenstadt's (1954) first phases of assimilation (acquisition of language, performing a set of new roles, and developing a new identity) but are in contradiction with the last phase (participating in the institutions of the host society). Our study shows a pronounced incompatibility in the final phase, behavior and identity adjustment. Given our data, it seems that our participants remained largely in the first phase as defined by Eisenstadt, because these refugee women remained preoccupied with the emergency that had entered their lives. They were suddenly involved in work for which they had not been prepared, requiring abilities and skills they had never used before, in circumstances that were incompatible with the culture that they had been forced to leave.

The findings of our study are also consistent with those of Mubayyed (2010), who revealed that the refugees in the Balata camp in the West Bank felt politically alienated, isolated, rebellious, and not adapted. In that vein, our study shows that the Syrian refugee women who were living outside the camps also suffered from a state of alienation and non-assimilation. This state correlated with their long-standing nostalgia for their homeland; the necessity to work hard because of economic difficulties, to which they were unaccustomed; and their desire to return to Syria, despite the difficult situation there.

\section{Conclusion and Recommendations}

The results of this study, which addressed the problematic issues of assimilation and identity, indicate that there are many internal and external factors and influences that correlate with refugee women being unable to integrate fully into the social life of Jordan, the country of asylum, despite having lived there for years.

The study also shows both hesitancy by refugee women to declare their Syrian identity to Jordanians, and a lack of Jordanian acceptance of the Syrian identity, even when it comes to Syrian women who have spent years in Jordan with their husbands and children. Moreover, when assimilation into the new society has not been achieved, the impact of this failure is made manifest in the identity of the Syrian refugee women, and in their inability to accept the new living situation. Often, the Syrian refugee women had not developed the new identity necessary to fit in with the asylum community, and to participate in social institutions in roles that they had not previously been familiar with. Additionally, the asylum trauma of the Syrian refugee women has a strong influence on their social relationships in the wider community.

Our study has revealed an interactive set of experiences lived by the refugee women residing outside the refugee camps. These experiences include: difficult economic circumstances, which resulted in challenges that were new in their lives; internal and external violence, a result of the difficult conditions and pressures of asylum; and psychological and social alienation from the new society, which resulted from the failure to assimilate and the distortion of the general identity of refugee women. 
The results of our study show that many Syrian women refugees living outside the camps are suffering an identity crisis, and are having difficulty assimilating. Therefore, it is recommended that public, international, and local associations and organizations pay attention to the cultural, social, and psychological assimilation of refugee women in the asylum society and work to empower them to become involved in the host culture. This can be achieved through organizations holding workshops to provide psychological and social support, as well as informing refugee women of the nature and conditions of the hosting environment. These measures would help to speed up the process of assimilation, in addition to avoiding fragmentation in terms of identity. 
International Journal of Child, Youth and Family Studies (2019) 10(4.1): 44-64

\section{References}

Abdul-Ghani, E. (2016). Sociology of culture. Beirut, Lebanon: Center for Arab Unity Studies.

Al-Salahat, A. (2014). المشكلات النفسية والاجتماعية التي تو اجه اللاجئات السوريات في مخيم الزعتري [The social and psychological problems that the Syrian Refugee women encounter in Zaatari Camp: A field study] (Unpublished master's thesis). University of Jordan, Amman, Jordan.

Al-Zabn, S. (2007). هوية الاجئين في ثقافتهم ولغتهم المحكية. بحث مقارن ما بين الجيل الثاني والثالث للنكبة: مخيم [The refugee identity in their culture and their dialect: A comparative paper between $2^{\text {nd }}$ and $3^{\text {rd }}$ generation of refugees]. $1^{\text {st }}$ edition. Palestinian Center for Citizenship and Refugee Rights.

Al-Zein, S. (2007). The refugee identity in their culture and their dialect: A comparative paper.

Alba, R., \& Nee, V. (2003). Remaking the American mainstream: Assimilation and contemporary immigration. Cambridge, MA. Harvard University Press.

Aqeel, H. (2013). العنف الو اقع على المر أة ابان الحروب و النزاعات المسلحة [Violence Against women during wars and armed conflict (Unpublished master's thesis). University of Jordan, Amman, Jordan.

Arokach, A. (2006). Alienation and domestic abuse: How abused women cope with loneliness. Social Indicators Research, 78(2), 327-340. doi:10.1007/s11205-005-1603-X

Avayah, M. N. (1986). Identity and difference. Casablanca, Morocco: Okaz Publishers/Orient Africa.

Baskauskas, L. (1981), The Lithuanian refugee experience and grief. International Migration Review, 15(1-2), 276-291. doi:10.1177/0197918381015001-227

Eisenstadt, S. N. (1954) The absorption of immigrants. London, UK: Routledge \& Kegan.

Ermann, M. (2004). Proceedings of the $54^{\text {th }}$ Lindau psychotherapy week. Conference held in Munich, Germany.

Ghalioun, B. (2006). غليون، برهان. إغتيال العقل، المركز الثقافي العربي العربي طـ 4 [The assassination of the mind: The plight of Arab culture between Salafism and subordination ( ${ }^{\text {th }}$ edition)]. Arab Cultural Center.

Gordon, M. M. (1964). Assimilation in American life: The role of race, religion, and national origins. New York, NY: Oxford University Press.

Haidar, A. (1997). Identity reproduction. Damascus, Syria: Dar al-Hassad for Publication and Distribution. 
International Journal of Child, Youth and Family Studies (2019) 10(4.1): 44-64

Halliday, F. (2000). Nation and religion in the Middle East (A.-E. al-Nae'mi, Trans.). Beirut, Lebanon: Dar al-Saqi.

Hyndman, J. (1999). Gender and Canadian immigration policy: A current snapshot. Canadian Woman Studies, 19(3), 6-10.

Kinnvall, C. (2004). Globalization and religious nationalism: Self, identity, and the search for ontological security. Political Psychology, 25(5), 741-767. doi:10.1111/j.14679221.2004.00396.x

Lockhart, D., \& Barker, K. (2018). Syrian Refugees and Social Cohesion in Jordan. Amman, Jordan: West Asia-North Africa Institute. Reviewed from http://wanainstitute.org/sites/default/files/publications/Publication_SocialCohesion_English -

Ma'alouf, A. (1999). The killing identities: Readings in belonging and globalization, (N. Muhsen, Trans.). Damascus, Syria: Dar Ward.

Mikshelly, A. (1993). Identity (A. Watfa, Trans.). Damascus, Syria: The French Publishing House.

Mubayyed, H. (2010). Palestinian refugees between alienation and political integration: "Case Study Balata Camp" (Master's thesis). Al-Najah National University, Nablus, Palestine. Retrieved from https://staff-old.najah.edu/raid/supervision/palestinian-refugees-betweenalienation-and-integration-\%E2\%80\%9Ccase-study-balata-camp \%E2\%80\%9D

Murphy, H. B. M. (1955). Introduction: The extent of the problem. In H. B. M. Murphy ( Ed.), Flight and resettlement (pp. 11-24). Paris, France: UNESCO.

Portes, A., \& Rumbaut, R. G. (2001). Legacies: The story of the immigrant second generation. Berkeley, CA: University of California Press.

Rashedi, H. T. (1999). Psychological stress: Nature and theories. Cairo, Egypt: Al-Angelo library.

Sisterhood is Global Institute Jordan. (2013). Press release No. 151. Amman, Jordan.

Taylor, R. \& Nathan, D. (1980, May). Resettlement casework: The role of the professional. Paper presented at the annual meeting of the Conference of Jewish Communal Service, Denver, Colorado.

UNICEF. (2015). Report on the joint field visit of the executive boards of UNDP / UNFPA / UNOPS, UNICEF, UN-Women and WFP to Amman, Jordan, 2 May 2015. Retrieved from https://www.unicef.org/about/execboard/files/2015_JFV_Report_to_Jordan-ar.pdf 
International Journal of Child, Youth and Family Studies (2019) 10(4.1): 44-64

UNHCR. (2014). نساء بمفردهن: صراع اللاجئات السوريات من اجل البقاء [Woman alone: The fight for survival by Syria's refugee women]. Retrieved from https://www.refworld.org/pdfid/53be84aa4.pdf

UNHCR. (2019). الاستعر اض العام لأوضاع الأجئين السوريين في الاردن [General review of Syrian refugees in Jordan]. Retrieved from https://www.unhcr.org/ar/4be7cc278c8.html

United Nations Population Fund. (2016). More than numbers. Regional overview: Responding to gender-based violence in the Syrian crisis. Amman, Jordan: UNFPA Syria Regional Response Hub. Retrieved from https://reliefweb.int/report/syrian-arab-republic/morenumbers-regional-overview-responding-gender-based-violence-syrian

Waters, M. C., Tran, V. C., Kasinitz, P., \& Mollenkopf, J. H. (2010). Segmented assimilation revisited: Types of acculturation and socioeconomic mobility in young adulthood. Ethnic and Racial Studies, 33(7), 1168-1193. doi:10.1080/01419871003624076

Zwingmann, C. (1978). Uprooting and related phenomena: A descriptive bibliography. Geneva, Switzerland: World Health Organization.

Za'arour, R. (2014, December 11). خارطة اللجوء السوري في الاردن [Syrian refugee map in Jordan]. NOWK. 